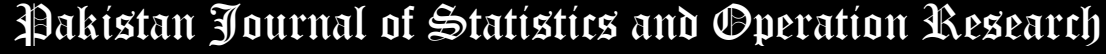

\section{A New Compound Version of the Generalized Lomax Distribution for Modeling Failure and Service Times}

\author{
S. I. Ansari ${ }^{1}$, Rezk H. ${ }^{2}$, Haitham M. Yousof ${ }^{3 *}$
}

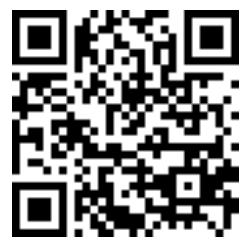

* Corresponding Author

1. Department of statistics, Faculty of Science, University of Tabuk, Tabuk, Kingdom of Saudi Arabia. Department of Business Administration Azad Institute of Engineering and Technology, Lucknow, India, saiful.islam.ansari@gmail.com

2. Mathematical Sciences Department, College of Science, Princess Nourah bint Abdulrahman University, Riyadh, Saudi Arabia. Department of Statistics, Al-Azhar University, Cairo, Egypt. hrmohamed@pnu.edu.sa 3. Department of Statistics, Mathematics and Insurance, Benha University, Egypt, haitham.yousof@fcom.bu.edu.eg

\begin{abstract}
The main goal of this article is to introduce a new extension of the continuous Lomax distribution with a strong physical motivation. Some of its statistical properties such as moments, incomplete moments, moment generating function, quantile function, random number generation, quantile spread ordering and moment of the reversed residual life are derived. Two applications are provided to illustrate the importance and flexibility of the new model.
\end{abstract}

Key Words: Maximum Likelihood Estimation; Quantile Function; Generating Function; Moments; Zero Truncated Poisson.

Mathematical Subject Classification: 62E10; 62N01; 62N02.

\section{Introduction}

\section{Introduction and physical motivation}

In this work, we develop and study a new univariate extension of the generalized Lomax (GLx) model by compounding the Rayleigh generalized Lomax (RGLx) model with the zero truncated Poisson (ZTP) distribution. Due to Yousof et al. (2017), a random variable (r.v.) $W$ is said to have the RGLx distribution if its cumulative distribution function $(\mathrm{CDF})$ is given

$$
F_{R G L x}^{(c, a, b)}(w)=1-\exp \left[-\left(\left\{1-\left[1+\left(\frac{w}{b}\right)\right]^{-a}\right\}^{-c}-1\right)^{-2}\right]
$$

where the CDF and probability density function (PDF) of the GLx distribution are

and

$$
\Pi_{c}(a, b)=G_{G L x}^{(c, a, b)}(w)=\left\{1-\left[1+\left(\frac{w}{b}\right)\right]^{-a}\right\}^{c},
$$

respectively.

$$
\pi_{c}(a, b)=g_{G L x}^{(c, a, b)}(w)=c a b^{-1}\left[1+\left(\frac{w}{b}\right)\right]^{-a-1}\left\{1-\left[1+\left(\frac{w}{b}\right)\right]^{-a}\right\}^{c-1},
$$


For $c=1$, we have the standard two-parameters Lx distribution (see Lomax (1954)). When $c=b=1$, we have the standard one-parameters Lx distribution. The probability mass function (PMF) of $U$ (where $U \sim \operatorname{ZTP}(\lambda)$ ) is given by

$$
P M F_{Z T P}^{(\lambda)}(U \mid U=n)=\left[\exp (-\lambda) \lambda^{n}\right] /\left.\left(n ! Y_{[\lambda]}\right)\right|_{(n=1,2, \ldots)},
$$

where $Y_{[\lambda]}=[-\exp (-\lambda)+1]$. Then the conditional CDF of $W$ given $U$ where

$$
W \mid U=\min \left\{Y_{1}, Y_{2}, \cdots, Y_{U}\right\},
$$

using (1) is

$$
F(w \mid U)=1-\operatorname{Pr}(W>w \mid U)=-\left[1-F_{R G L x}^{(c, a, b)}(w)\right]^{U}+1
$$

The unconditional CDF of the PRGLx PDF can be written as

$$
F(w)=F_{P R G L x}^{(\lambda, c, a, b)}(w)=\frac{1}{Y_{[\lambda]}}\left[1-\exp \left(-\lambda\left\{1-\exp \left[-\left(\left\{1-\left[1+\left(\frac{w}{b}\right)\right]^{-a}\right\}^{-c}-1\right)\right]\right\}\right),\right.
$$

with corresponding PDF as

$$
\begin{aligned}
& f(w)=f_{P R G L x}^{(\lambda, c, a, b)}(w)=\frac{2 \lambda c a\left\{1-\left[1+\left(\frac{w}{b}\right)\right]^{-a}\right\}^{2 c-1}}{\gamma_{[\lambda]} b\left(1-\left\{1-\left[1+\left(\frac{w}{b}\right)\right]^{-a}\right\}^{c}\right)^{3}} \\
& \times\left[1+\left(\frac{w}{b}\right)\right]^{-a-1} \exp \left[-\left(\left\{1-\left[1+\left(\frac{w}{b}\right)\right]^{-a}\right\}^{-c}-1\right)^{-2}\right] \\
& \times \exp \left(-\lambda\left\{1-\exp \left[-\left(\left\{1-\left[1+\left(\frac{w}{b}\right)\right]^{-a}\right\}^{-c}-1\right)^{-2}\right]\right\}\right)
\end{aligned}
$$

The plots of the PRGLx PDF and HRF are displayed in Fig.s 1 and 2 for selected parameter values. From Fig.s 1 and 2 we conclude that the PRGLx distribution may be suitable in modeling right skewed, left skewed, symmetric and unimodal data sets. The HRF of the PRGLx may have the increasing, J-shapes, upside down then bathtub, upside down then increasing, upside down and bathtub (U-shape).
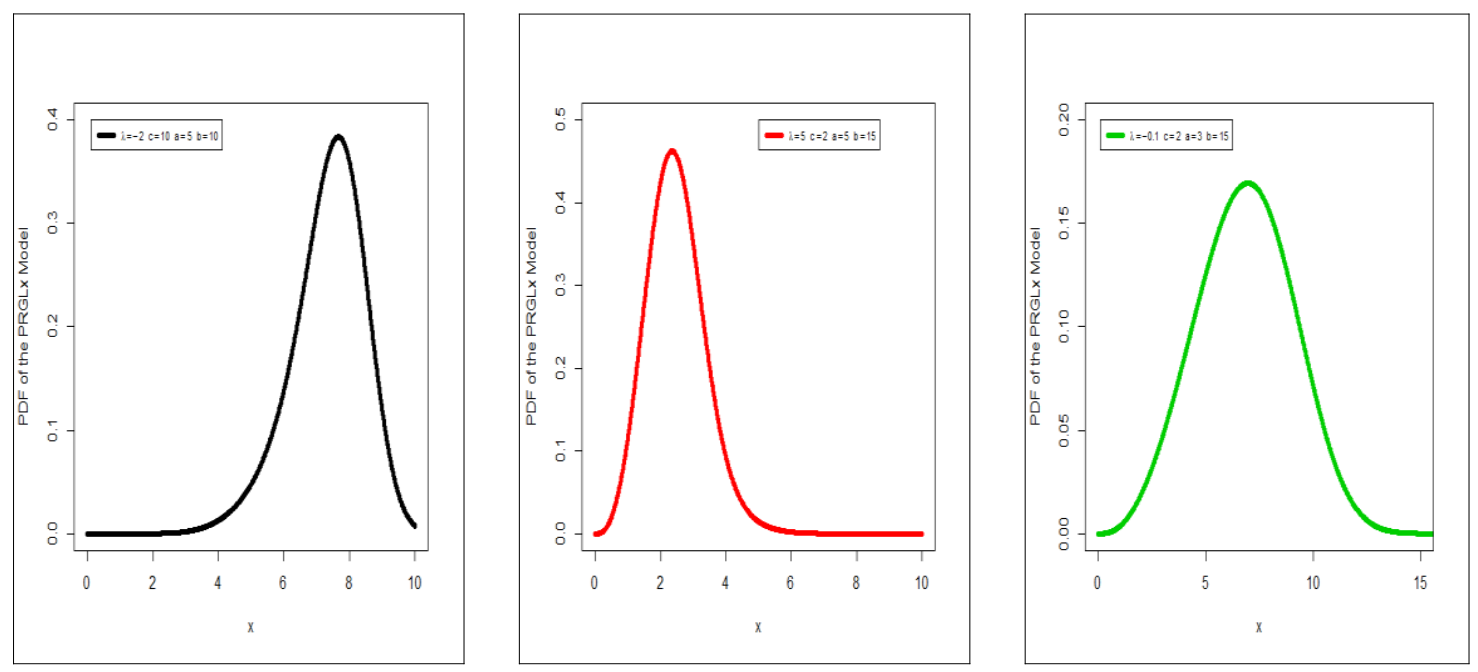

Figure 1: Some PDF plots for the PRGLx model. 

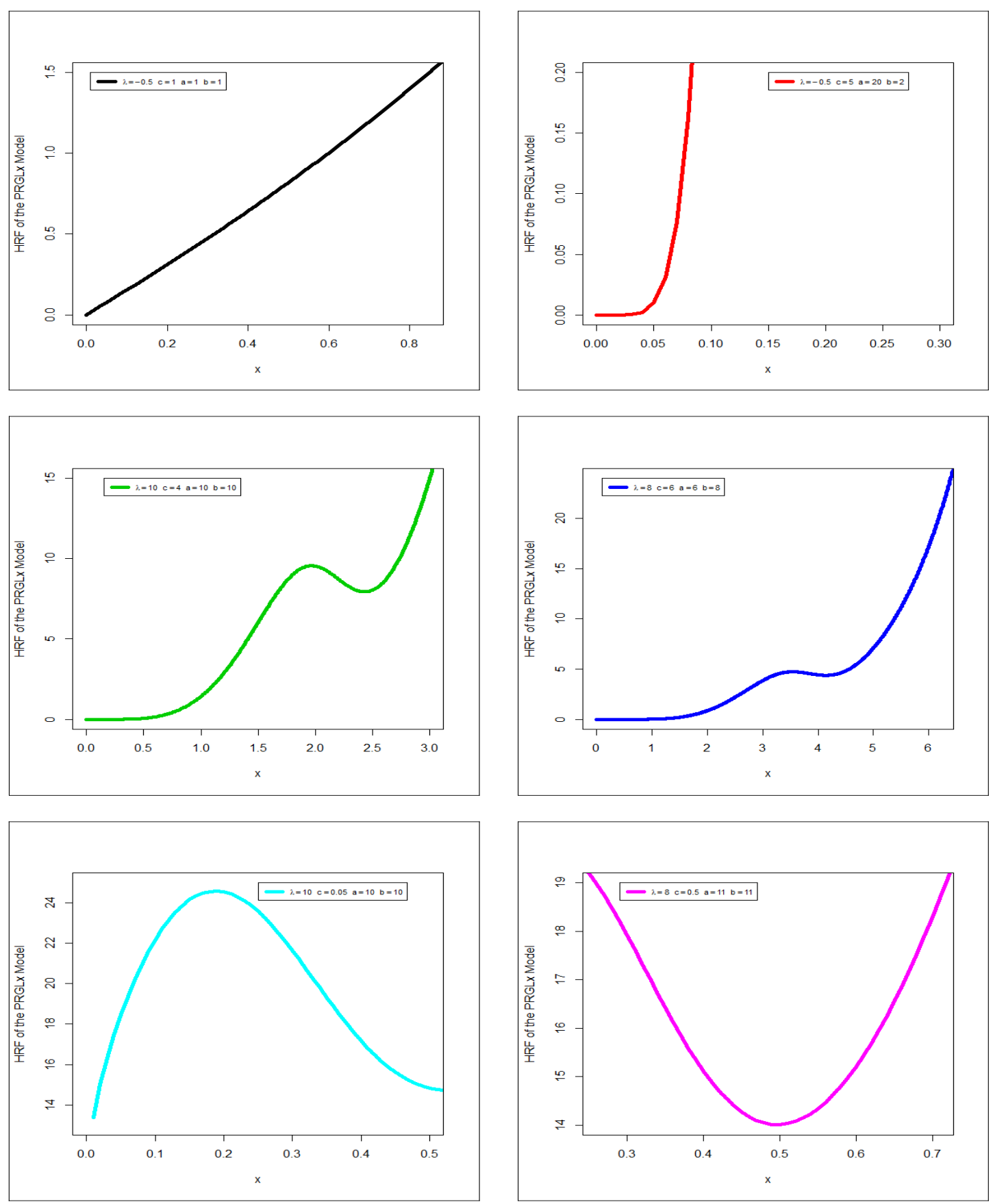

Figure 2: Some HRF plots for the PRGLx model.

Some useful versions of the Lx model have been recently developed by Yousof et al. (2015), Brito et al. (2017), Cordeiro et al. (2018), Altun et al. (2018a), Altun et al. (2018b), Yousof et al. (2018a-e, 2019a-b), Ibrahim et al. (2019), Gad et al. (2019) and Goual and Yousof (2019), Hamedani et al. (2017, 2018, 2019), Ibrahim, M. (2019, 2020a-b) Korkmaz et al. (2017, 2018, 2019), and Ibrahim et al. (2019, 2020). 


\section{Mathematical properties}

2.1 Useful expansions

Using the power series

$$
\exp \left(\varphi_{1}\right)=\sum_{p=0}^{\infty} \frac{1}{p !} \varphi_{1}^{p}
$$

the PDF in (6) can be written as

$$
\begin{aligned}
& f(w)=2 c a \sum_{\zeta_{3}=0}^{\infty} \lambda^{1+\zeta_{3}} \frac{(-1)^{\zeta_{3}}}{\zeta_{3} ! b \gamma_{[\lambda]}} \\
& \times \frac{\left[1+\left(\frac{w}{b}\right)\right]^{-a-1}\left\{1-\left[1+\left(\frac{w}{b}\right)\right]^{-a}\right\}^{2 c-1}}{\left(1-\left\{1-\left[1+\left(\frac{w}{b}\right)\right]^{-a}\right\}^{c}\right)^{3}} \\
& \times \exp \left[-\left(\left\{1-\left[1+\left(\frac{w}{b}\right)\right]^{-a}\right\}^{-c}-1\right)^{-2}\right] \\
& \times\left\{1-\exp \left[-\left(\left\{1-\left[1+\left(\frac{w}{b}\right)\right]^{-a}\right\}^{-c}-1\right)^{-2}\right]\right\}^{\zeta_{3}}
\end{aligned}
$$

If $\left|\varphi_{1}\right|<1$ and $\varphi_{2}>0$ is a real non-integer, then

$$
\left(1-\varphi_{1}\right)^{\varphi_{2}-1}=\sum_{m=0}^{\infty} \frac{1}{m ! \Gamma\left(\varphi_{2}-m\right)}\left(-\varphi_{1}\right)^{m} \Gamma\left(\varphi_{2}\right) .
$$

Applying (8) to (7) we have

$$
\begin{aligned}
& f(w)=\frac{2 c a \lambda^{1+\zeta_{3}}}{b \gamma_{[\lambda]}}\left(1-\left\{1-\left[1+\left(\frac{w}{b}\right)\right]^{-a}\right\}^{c}\right)^{3} \\
& \times\left[1+\left(\frac{w}{b}\right)\right]^{-a-1}\left\{1-\left[1+\left(\frac{w}{b}\right)\right]^{-a}\right\}^{2 c-1} \\
& \times \sum_{\zeta_{3}, \zeta_{4}=0}^{\infty} \frac{(-1)^{\zeta_{3}+\zeta_{4}} \Gamma\left(c\left(\zeta_{3}+1\right)\right)}{\zeta_{4} ! \Gamma\left(c\left(\zeta_{3}+1\right)-\zeta_{4}\right)} \\
& \times \exp \left[-\left(\zeta_{4}+1\right)\left(\left\{1-\left[1+\left(\frac{w}{b}\right)\right]^{-a}\right\}^{-c}-1\right)^{-2}\right]
\end{aligned}
$$

Applying the power series to

Equation (9) can be written as

$$
\exp \left[-\left(\zeta_{4}+1\right)\left(\left\{1-\left[1+\left(\frac{w}{b}\right)\right]^{-a}\right\}^{-c}-1\right)^{-2}\right]
$$

$$
\begin{aligned}
& f(w)=\sum_{\zeta_{3}, \zeta_{4}, \zeta_{1}=0}^{\infty} 2 \lambda^{1+\zeta_{3}} \frac{(-1)^{\zeta_{3}+\zeta_{4}+\zeta_{1}}\left(\zeta_{4}+1\right)^{\zeta_{1}} \Gamma\left(\zeta_{3}+1\right)}{\zeta_{4} ! \zeta_{1} ! Y_{[\lambda]} \Gamma\left(\zeta_{3}+1-\zeta_{4}\right)} \\
& \times a b^{-1} c\left[1+\left(\frac{w}{b}\right)\right]^{-a-1}\left\{1-\left[1+\left(\frac{w}{b}\right)\right]^{-a}\right\}^{c-1} \\
& \times \frac{\left(\left\{1-\left[1+\left(\frac{w}{b}\right)\right]^{-a}\right\}^{c}\right)^{2 \zeta_{1}+1}}{\left(1-\left\{1-\left[1+\left(\frac{w}{b}\right)\right]^{-a}\right\}^{c}\right)^{2 \zeta_{1}+3}} .
\end{aligned}
$$

Consider the series expansion 


$$
\left.\left(1-\varphi_{1}\right)^{-\varphi_{2}}\right|_{\left(\left|\varphi_{1}\right|<1, \varphi_{2}>0\right)}=\sum_{w=0}^{\infty} \frac{\Gamma\left(\varphi_{2}+w\right)}{w ! \Gamma\left(\varphi_{2}\right)} \varphi_{1}{ }^{w} .
$$

Applying (11) to

Equation (10) becomes

$$
\left(1-\left\{1-\left[1+\left(\frac{w}{b}\right)\right]^{-a}\right\}^{c}\right)^{-2 \zeta_{1}-3}
$$

$$
\begin{aligned}
& f(w)=\sum_{\substack{\zeta_{1}, \zeta_{2}, \zeta_{3}, \zeta_{4}=0 \\
\Gamma\left(\zeta_{3}+1\right) \Gamma\left(3+2 \zeta_{1}+\zeta_{2}\right)}}^{\infty} 2 \lambda^{1+\zeta_{3}} \frac{(-1)^{\zeta_{3}+\zeta_{4}+\zeta_{1}}\left(\zeta_{4}+1\right)^{\zeta_{1}}}{\zeta_{4} ! \zeta_{1} ! \zeta_{2} ! Y_{[\lambda]}} \\
& \times \frac{\Gamma\left(\zeta_{3}+1-\zeta_{4}\right) \Gamma\left(2 \zeta_{1}+3\right)\left[2\left(\zeta_{1}+1\right)+\zeta_{2}\right]}{\times a b^{-1} c\left[2\left(\zeta_{1}+1\right)+\zeta_{2}\right]\left[1+\left(\frac{w}{b}\right)\right]^{-a-1}} \\
& \times\left\{1-\left[1+\left(\frac{w}{b}\right)\right]^{-a}\right\}^{c\left[2\left(\zeta_{1}+1\right)+\zeta_{2}\right]-1} .
\end{aligned}
$$

This can be written as

$$
f(w)=\sum_{\zeta_{1}, \zeta_{2}=0}^{\infty} v_{\left[\zeta_{1}, \zeta_{2}\right]} \pi_{\mathbf{c}^{*}}(w ; a, b),
$$

where $\mathbf{c}^{*}=c\left[2\left(1+\zeta_{1}\right)+\zeta_{2}\right]$ and

and

$$
\begin{aligned}
& v_{\left[\zeta_{1}, \zeta_{2}\right]}=\frac{2 \lambda^{1+\zeta_{3}}(-1)^{\zeta_{1}} \Gamma\left(3+2 \zeta_{1}+\zeta_{2}\right)}{\zeta_{1} ! \zeta_{2} ! Y_{[\lambda]} \Gamma\left(2 \zeta_{1}+3\right)\left[2\left(1+\zeta_{1}\right)+\zeta_{2}\right]} \\
& \times \sum_{\zeta_{3}, \zeta_{4}=0}^{\infty} \frac{(-1)^{\zeta_{3}+\zeta_{4}} \Gamma\left(\zeta_{3}+1\right)\left(\zeta_{4}+1\right)^{\zeta_{1}}}{\zeta_{4} ! \Gamma\left(\zeta_{3}+1-\zeta_{4}\right)}
\end{aligned}
$$

$$
\pi_{\mathbf{c}^{*}}(w ; \phi)=\frac{a \mathbf{c}^{*}}{b}\left[1+\left(\frac{w}{b}\right)\right]^{-a-1}\left\{1-\left[1+\left(\frac{w}{b}\right)\right]^{-a}\right\}^{\mathbf{c}^{*}-1}
$$

which is the PDF of the GLx model with power parameter $\mathbf{c}^{*}$. Similarly

where

$$
F(w)=\sum_{\zeta_{1}, \zeta_{2}=0}^{\infty} v_{\left[\zeta_{1}, \zeta_{2}\right]} \Pi_{\mathbf{c}^{*}}(w ; a, b),
$$

is the CDF of the GLx model with power parameter $\mathbf{c}^{*}$.

$$
\Pi_{\mathbf{c}^{*}}(w ; a, b)=\left\{1-\left[1+\left(\frac{w}{b}\right)\right]^{-a}\right\}^{\mathbf{c}^{*}}
$$

\subsection{Moments and incomplete moments}

Let $Y$ be a continuous r.v. having the GLx model with power parameter $\varphi$, then the $q^{\text {th }}$ ordinary and incomplete moments $\left(\mu_{q}^{\prime}(y)\right.$ and $\left.m_{q}(y)\right)$ of the GLx r.v. (defined in this subsection) given by

and

$$
\mu_{q}^{\prime}(y)=\left.\sum_{h=0}^{q} \varphi b^{q}(-1)^{h}\left(\begin{array}{c}
q \\
w
\end{array}\right) B\left(\varphi, \frac{h-q}{a}+1\right)\right|_{(a>q)},
$$

where

$$
m_{q}(y)=\left.\sum_{h=0}^{q} \varphi b^{q}(-1)^{h}\left(\begin{array}{c}
q \\
w
\end{array}\right) B_{t}\left(\varphi, \frac{h-q}{a}+1\right)\right|_{(a>q)}
$$


is the complete beta function and

$$
\left.B\left(a_{1}, a_{2}\right)\right|_{\left[a_{1}, a_{2} \notin(0,-1,-2, \ldots)\right]}=\int_{0}^{1} u^{a_{1}-1}(1-u)^{a_{2}-1} d u,
$$

$$
\left.B_{z}\left(a_{1}, a_{2}\right)\right|_{\left[a_{1}, a_{2} \notin(0,-1,-2, \ldots)\right]}=\int_{0}^{z} u^{a_{1}-1}(1-u)^{a_{2}-1} d u,
$$

is the incomplete beta function. The $r^{\text {th }}$ ordinary moment of $W$, say $\mu_{r}^{\prime}$, follows from (12) as

where

$$
\mu_{r}^{\prime}=E\left(W^{r}\right)=\left.\sum_{\zeta_{1}, \zeta_{2}=0}^{\infty} \sum_{h=0}^{r} \xi_{\zeta_{1}, \zeta_{2}, h}^{\left\{\mathbf{c}^{*}, r\right\}} B\left(\mathbf{c}^{*}, \frac{h-r}{a}+1\right)\right|_{(a>r)},
$$

Setting $r=1$ in (14) gives the mean of $W$ as

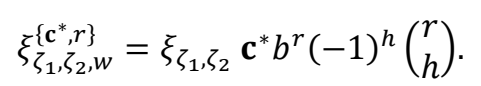

$$
\mu_{1}^{\prime}=E(W)=\left.\sum_{\zeta_{1}, \zeta_{2}=0}^{\infty} \sum_{h=0}^{1} \xi_{\zeta_{1}, \zeta_{2}, h}^{\left\{\mathbf{c}^{*}, 1\right\}} B\left(\mathbf{c}^{*}, \frac{h-1}{a}+1\right)\right|_{(a>1)},
$$

Setting $r=2,3$ and 4 in (14), we have the $2 n d, 3 r d$ and the 4 th moments about the origin

and

$$
\begin{aligned}
& \mu_{2}^{\prime}=E\left(W^{2}\right)=\left.\sum_{\zeta_{1}, \zeta_{2}=0}^{\infty} \sum_{h=0}^{2} \xi_{\zeta_{1}, \zeta_{2}, h}^{\left\{\mathbf{c}^{*}, 2\right\}} B\left(\mathbf{c}^{*}, \frac{h-2}{a}+1\right)\right|_{(a>2)}, \\
& \mu_{3}^{\prime}=E\left(W^{3}\right)=\left.\sum_{\zeta_{1}, \zeta_{2}=0}^{\infty} \sum_{h=0}^{3} \xi_{\zeta_{1}, \zeta_{2}, h}^{\left\{\mathbf{c}^{*}, 3\right\}} B\left(\mathbf{c}^{*}, \frac{h-3}{a}+1\right)\right|_{(a>3)}
\end{aligned}
$$

The $r^{\text {th }}$ incomplete moment of $W$ is defined by

$$
\mu_{4}^{\prime}=E\left(W^{4}\right)=\left.\sum_{\zeta_{1}, \zeta_{2}=0}^{\infty} \sum_{h=0}^{4} \xi_{\zeta_{1}, \zeta_{2}, h}^{\left\{\mathbf{c}^{*}, 4\right\}} B\left(\mathbf{c}^{*}, \frac{h-4}{a}+1\right)\right|_{(a>4)} .
$$

We can write from (12)

$$
m_{r}(q)=\int_{-\infty}^{q} u^{r} f(u) d u
$$

$$
m_{r}(w)=\left.\sum_{\zeta_{1}, \zeta_{2}=0}^{\infty} \sum_{h=0}^{r} \xi_{\zeta_{1}, \zeta_{2}, h}^{\left\{\mathbf{c}^{*}, r\right.} B_{t}\left(\mathbf{c}^{*}, \frac{h-r}{a}+1\right)\right|_{(a>r)},
$$

The first incomplete moment $m_{1}(y)$ can derived as

$$
m_{1}(y)=\left.\sum_{\zeta_{1}, \zeta_{2}=0}^{\infty} \sum_{h=0}^{1} \quad \xi_{\zeta_{1}, \zeta_{2}, h}^{\{*} B_{t}\left(\mathbf{c}^{*}, \frac{h-1}{a}+1\right)\right|_{(a>1)}
$$

\subsection{Generating function}

The moment generating function (mgf) of $W$, say $M_{W}(t)=E(\exp (t W))$, is obtained from (12) as

$$
M_{W}(t)=\left.\sum_{\zeta_{1}, \zeta_{2}, r=0}^{\infty} \sum_{h=0}^{r} \frac{t^{r}}{r !} \xi_{\zeta_{1}, \zeta_{2}, h}^{\left\{\mathbf{c}^{*}, r\right\}} B\left(\mathbf{c}^{*}, \frac{h-r}{a}+1\right)\right|_{(a>r)} .
$$

\subsection{Quantile function (qf) and random number generation}

The qf of $W$, where $W \sim \operatorname{PRGLx}(\lambda, c, a, b)$, is obtained by inverting (4) as 


$$
Q(u)=b\left\{\left[1-\left(1+\left\{-\ln \left[1+\frac{\ln \left(1-u Y_{[\lambda]}\right)}{\lambda}\right]\right\}^{\frac{1}{2}}\right)^{\frac{1}{c}}\right]^{-\frac{1}{a}}-1\right\}
$$

\subsection{Moment of the reversed residual life}

The $n^{\text {th }}$ moment of the reversed residual, say

Then, we have

$$
r_{n}(t)=\left.E\left[(t-W)^{n}\right]\right|_{(W \leq t, t>0)} ^{(n=1,2, \ldots)} .
$$

Then

$$
Y_{n}(t)=F^{-1}(t) \int_{0}^{t}(t-w)^{n} d F(w)
$$

where

$$
Y_{n}(t)=\left.F^{-1}(t) \sum_{\zeta_{1}, \zeta_{2}=0}^{\infty} \sum_{h=0}^{n} \sum_{r=0}^{n} \xi_{\zeta_{1}, \zeta_{2}, w h, r}^{\left\{\mathbf{c}^{*}, n\right\}} B_{t}\left(\mathbf{c}^{*}, \frac{h-n}{a}+1\right)\right|_{(a>n)},
$$

$$
\xi_{\zeta_{1}, \zeta_{2}, w, r}^{\left\{\mathbf{c}^{*}, n\right\}}=\xi_{\zeta_{1}, \zeta_{2}}(-1)^{r} t^{n-r} \mathbf{c}^{*} b^{n}(-1)^{h}\left(\begin{array}{l}
n \\
h
\end{array}\right)\left(\begin{array}{l}
n \\
r
\end{array}\right) \text {. }
$$

\section{Estimation}

The $\log$-likelihood function for $\Phi$ is given by

$$
\begin{aligned}
& \ell_{n}(\Phi)=n \log 2+n \log c+n \log \lambda+n \log a \\
& -\sum_{h=1}^{n}\left(\frac{\left\{1-\left[1+\left(\frac{w_{h}}{b}\right)\right]^{-a}\right\}^{c}}{1-\left\{1-\left[1+\left(b^{-1} w_{h}\right)\right]^{-a}\right\}^{c}}\right)^{2} \\
& -n \log b-(a+1) \sum_{h=1}^{n} \log \left[1+\left(\frac{w_{h}}{b}\right)\right] \\
& -3 \sum_{h=1}^{n} \log \left(1-\left\{1-\left[1+\left(\frac{w_{h}}{b}\right)\right]^{-a}\right\}^{c}\right) \\
& -n \log Y_{[\lambda]}+(2 c-1) \sum_{h=1}^{n} \log \left\{1-\left[1+\left(\frac{w_{h}}{b}\right)\right]^{-a}\right\} \\
& -\lambda \sum_{h=1}^{n}\left\{1-\exp \left[-\left(\frac{\left\{1-\left[1+\left(\frac{w_{h}}{b}\right)\right]^{-a}\right\}^{c}}{1-\left\{1-\left[1+\left(\frac{w_{h}}{b}\right)\right]^{-a}\right\}^{c}}\right)^{2}\right]\right\}
\end{aligned}
$$

The above log-likelihood function can be maximized numerically by via R (optim) or SAS (PROC NLMIXED) or Ox program (sub-routine MaxBFGS).

\section{Modeling data}

In this section, we provide two applications to show empirically the potentiality of the PRGLx model. In order to compare the fits of the PRGLx distribution with other competing distributions, we consider the Cramér-Von-Mises ( $\left.W^{*}\right)$ and the Anderson-Darling $\left(A^{*}\right)$ statistics. We compare the fit of the new model with competitive models namely: The ZTP Burr-X Lomax (ZTPBrXLx); the BrXLx; GLx model; the gamma Lomax (GLx) model; the beta Lomax (BLX) model and Lx model. The MLEs and the corresponding standard errors (in parentheses) of the model parameters are given in Tables 1 and 3. The statistics $W^{*}$ and $A^{*}$ are listed in Tables 2 and 4 . The Estimated PDF, P-P plot, TTT plot, estimated HRF and and and Kaplan-Meier survival plot of the two data sets and the estimated PDF of the proposed model are displayed in Fig.s 3 and 4.

\subsection{Modeling failure times}


This data set represents the data on failure times of 84 aircraft windshield given in application 1. From table 2 and Fig. 3, the PRGLx lifetime model is much better than the ZTP Burr-X Lx, the Burr-X Lx, gamma Lx, beta Lx, GLx and Lx models so the PRGLx model is a good alternative to these models in modeling aircraft windshield data.

Table 1: MLEs (standard errors in parentheses) for data set $\mathbf{I}$.

\begin{tabular}{|c|c|c|c|c|}
\hline Model & \multicolumn{4}{|c|}{ Estimates } \\
\hline PRGLx( $\boldsymbol{\lambda}, \mathbf{c}, \mathbf{a}, \mathbf{b})$ & $\mathbf{- 3 . 5 4 6}$ & $\mathbf{0 . 4 1 3 2}$ & $\mathbf{2 . 1 6 3 7}$ & $\mathbf{1 7 . 6 9 5}$ \\
\hline & $\mathbf{( 1 . 9 9 1 )}$ & $\mathbf{( 0 . 1 5 2 1 0}$ & $\mathbf{( 3 . 1 9 0 )}$ & $(\mathbf{2 7 . 7})$ \\
\hline $\operatorname{PBrXLx}(\lambda, \mathrm{c}, \mathrm{a}, \mathrm{b})$ & -5.2837 & 0.2860 & 1.553 & 4.6136 \\
\hline & $(93.989)$ & $(0.3119)$ & $(1.395)$ & $(5.843)$ \\
\hline $\operatorname{BLx}(\alpha, \beta, \mathrm{a}, \mathrm{b})$ & 3.6036 & 118.84 & 33.6387 & 4.8307 \\
\hline & $(0.619)$ & $(63.715)$ & $(9.2382)$ & $(429.0)$ \\
\hline $\operatorname{BrXLx}(\mathrm{c}, \mathrm{a}, \mathrm{b})$ & $5.24 \times \mathrm{e}^{5}$ & $8.23 \times \mathrm{e}^{-1}$ & $1.159 \times \mathrm{e}^{5}$ & \\
\hline & $(0.000)$ & $(0.10511)$ & $(5446.8)$ & \\
\hline $\operatorname{GLx}(\mathrm{c}, \mathrm{a}, \mathrm{b})$ & 3.6261 & 26257.681 & 20074.51 & \\
\hline & $(0.6236)$ & $(99.742)$ & $(2041.83)$ & \\
\hline $\operatorname{GaLx}(\lambda, \mathrm{a}, \mathrm{b})$ & 3.5876 & 37029 & 52001 & \\
\hline & $(0.5133)$ & $(81.16)$ & $(7955)$ & \\
\hline $\operatorname{Lx}(\mathrm{a}, \mathrm{b})$ & 131789 & 51425 & & \\
\hline & $(296.12)$ & $(5933.5)$ & & \\
\hline
\end{tabular}

Table 2: $W^{*}$ and $A^{*}$ for data set $\mathbf{I}$.

\begin{tabular}{|c|c|c|}
\hline $\operatorname{PRGLx}(\lambda, \mathrm{c}, \mathrm{a}, \mathrm{b})$ & $\mathbf{0 . 0 6 4 3}$ & $\mathbf{0 . 1 5 0 4}$ \\
\hline $\operatorname{ZTPBrXLx}(\lambda, \mathrm{c}, \mathrm{a}, \mathrm{b})$ & 0.0746 & 0.1531 \\
\hline $\operatorname{BrXLx}(\mathrm{c}, \mathrm{a}, \mathrm{b})$ & 0.0764 & 0.5844 \\
\hline $\operatorname{BLx}(\alpha, \beta, \mathrm{a}, \mathrm{b})$ & 1.4084 & 0.1680 \\
\hline $\operatorname{GLx}(\mathrm{c}, \mathrm{a}, \mathrm{b})$ & 1.7435 & 0.2194 \\
\hline $\operatorname{GaLx}(\lambda, \mathrm{a}, \mathrm{b})$ & 1.3667 & 0.1619 \\
\hline $\operatorname{Lx}(\mathrm{a}, \mathrm{b})$ & 1.3976 & 0.1665 \\
\hline
\end{tabular}



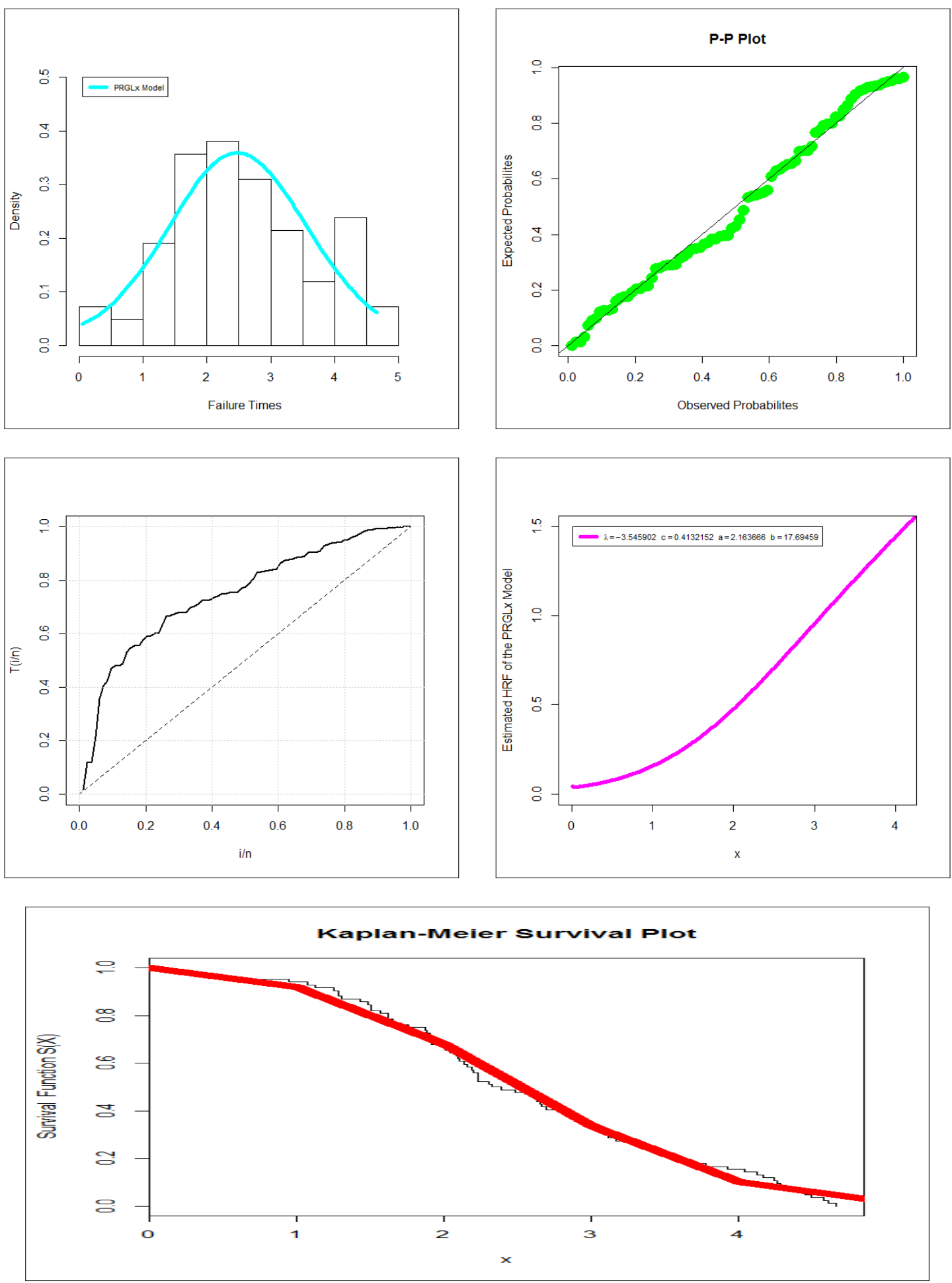

Fig. 3: Estimated-PDF, P-P plot, TTT plot, estimated-HRF and Kaplan-Meier plot for data $\mathbf{I}$. 


\subsection{Modeling service times}

This real data set represents the data on service times of 63 aircraft windshield given in Murthy et al. (2004). From table 4 and Fig. 4, the PRGLx lifetime model is much better than the ZTP Burr-X Lx, the Burr-X Lx, the gamma Lx, beta Lx, GLx and Lx models so the new PRGLx model is a good alternative to these models in modeling the service times data.

\begin{tabular}{|c|c|c|c|c|}
\hline \multicolumn{5}{|c|}{ Table 3: MLEs (standard errors in parentheses) for data set II. } \\
\hline Model & \multicolumn{4}{|c|}{ Estimates } \\
\hline PRGLx( $\boldsymbol{\lambda}, \mathbf{c}, \mathbf{a}, \mathbf{b})$ & $\mathbf{- 1 . 1 9 0 3}$ & $\mathbf{0 . 4 6 8}$ & $\mathbf{1 . 1 2 2 4}$ & $\mathbf{7 . 3 6 1}$ \\
\hline & $\mathbf{( 1 . 7 6 8 4 )}$ & $\mathbf{( 0 . 1 6 3 6 )}$ & $\mathbf{( 1 . 3 2 2})$ & $\mathbf{( 8 . 7 4 2 )}$ \\
\hline ZTPBrXLx$(\lambda, \mathrm{c}, \mathrm{a}, \mathrm{b})$ & -1.4557 & 0.4652 & 1.3517 & 3.9449 \\
\hline & $(2.303)$ & $(0.215)$ & $(91.499)$ & $(6.440)$ \\
\hline BLx $(\alpha, \beta, \mathrm{a}, \mathrm{b})$ & 1.9218 & 169.58 & 31.259 & 4.9685 \\
\hline & $(0.3185)$ & $(339.2)$ & $(316.8)$ & $(50.53)$ \\
\hline BrXLx $(\mathrm{c}, \mathrm{a}, \mathrm{b})$ & 0.6467 & 0.5987 & 1.6211 & \\
\hline & $(0.0475)$ & $(0.390)$ & $(0.959)$ & \\
\hline GLx $(\mathrm{c}, \mathrm{a}, \mathrm{b})$ & 1.9145 & 32881.9 & 22971.2 & \\
\hline & $(0.3483)$ & $(162.22)$ & $(3209.5)$ & \\
\hline
\end{tabular}

\begin{tabular}{|c|c|c|}
\hline \multicolumn{3}{|c|}{ Table $4: W^{*}$ and $A^{*}$ for data set I I. } \\
\hline PRGLx $(\boldsymbol{\lambda}, \mathbf{c}, \mathbf{a}, \mathbf{b})$ & $\mathbf{0 . 0 3 1 2}$ & $\mathbf{0 . 1 2 1 9}$ \\
\hline ZTPBrXLx $(\lambda, \mathrm{c}, \mathrm{a}, \mathrm{b})$ & 0.0337 & 0.1229 \\
\hline $\operatorname{BrXLx}(\mathrm{c}, \mathrm{a}, \mathrm{b})$ & 0.0876 & 0.5278 \\
\hline $\operatorname{BLx}(\alpha, \beta, \mathrm{a}, \mathrm{b})$ & 1.1336 & 0.1872 \\
\hline $\operatorname{GLx}(\mathrm{c}, \mathrm{a}, \mathrm{b})$ & 1.2331 & 0.2037 \\
\hline $\operatorname{GaLx}(\lambda, \mathrm{a}, \mathrm{b})$ & 1.1121 & 0.2038 \\
\hline $\operatorname{Lx}(\mathrm{a}, \mathrm{b})$ & 1.1265 & 0.1861 \\
\hline
\end{tabular}



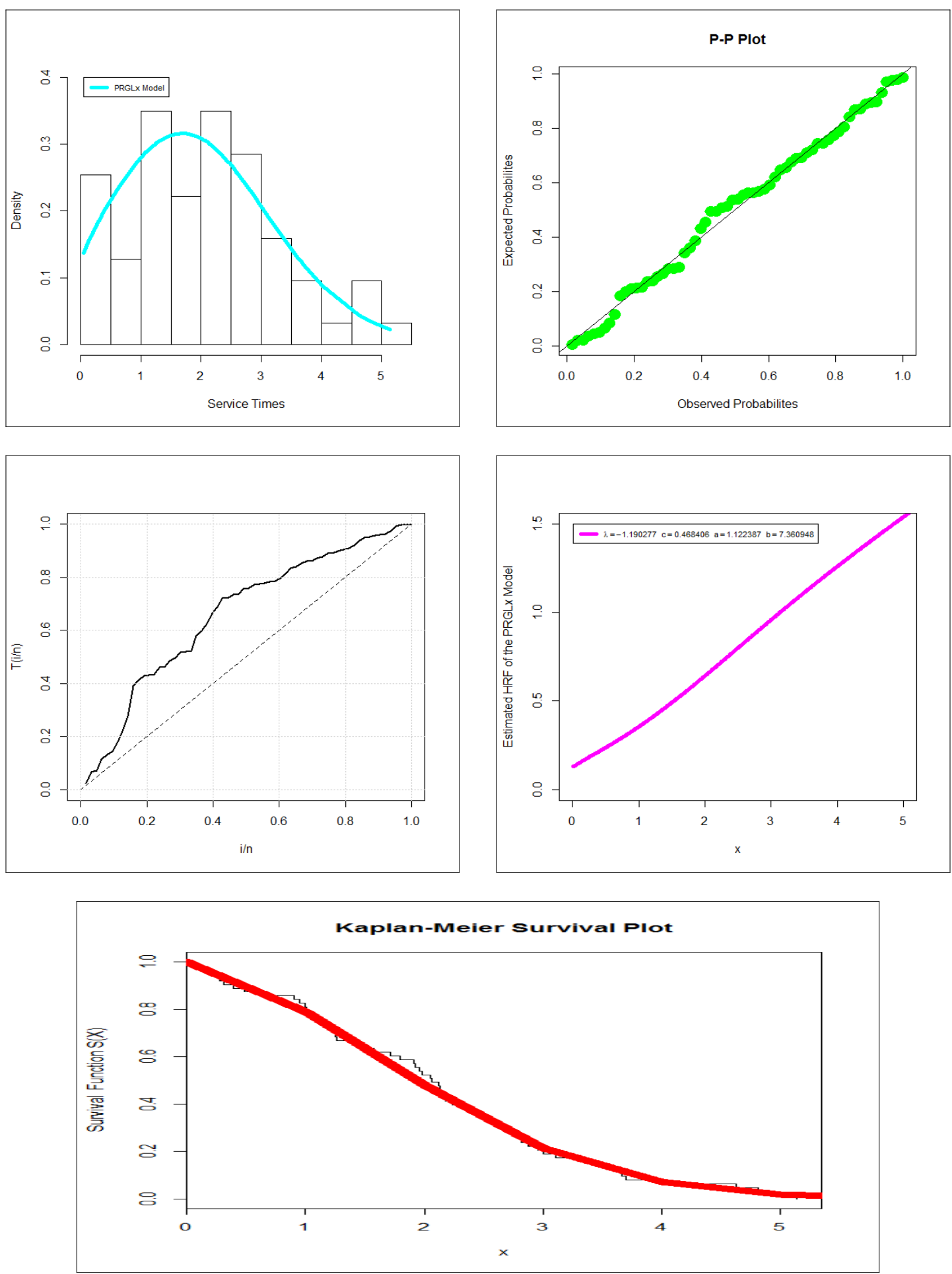

Fig. 4: Estimated-PDF, P-P plot, TTT plot, estimated-HRF and Kaplan-Meier plot for data II. 


\section{Concluding remarks}

In this paper, we introduced a new extension of the continuous Lomax distribution with a strong physical motivation. Some of its statistical properties such as moments, incomplete moments, moment generating function, quantile function, random number generation, quantile spread ordering and moment of the reversed residual life are derived. Two real data applications are provided to illustrate the importance and flexibility of the new model. The new lifetime model is much better than other competitive models such as the ZTP Burr-X Lomax, the Burr-X Lomax, the gamma Lomax, the beta Lomax, the generalized Lomax and the original Lomax model so the new model is a useful alternative to these models in modeling the failure and service times data.

\section{References}

1. Altun, E., Yousof, H. M. and Hamedani, G. G. (2018a). A new log-location regression model with influence diagnostics and residual analysis. Facta Universitatis, Series: Mathematics and Informatics, 33(3), 417-449.

2. Altun, E., Yousof, H. M., Chakraborty, S. and Handique, L. (2018b). Zografos-Balakrishnan Burr XII distribution: regression modeling and applications. International Journal of Mathematics and Statistics, 19(3), 46-70.

3. Brito, E., Cordeiro, G. M., Yousof, H. M., Alizadeh, M. and Silva, G. O. (2017). Topp-Leone Odd LogLogistic Family of Distributions, Journal of Statistical Computation and Simulation, 87(15), 3040-3058.

4. Corbellini, A., Crosato, L., Ganugi, P and Mazzoli, M. (2007). Fitting Pareto II distributions on firm size: Statistical methodology and economic puzzles. Paper presented at the International Conference on Applied Stochastic Models and Data Analysis, Chania, Crete.

5. Cordeiro, G. M., Yousof, H. M., Ramires, T. G. and Ortega, E. M. M. (2018). The Burr XII system of densities: properties, regression model and applications. Journal of Statistical Computation and Simulation, 88(3), 432-456.

6. Gad, A. M., Hamedani, G. G., Salehabadi, S. M. and Yousof, H. M. (2019). The Burr XII-Burr XII distribution: mathematical properties and characterizations. Pakistan Journal of Statistics, 35(3), 229-248.

7. Goual, H. and Yousof, H. M. (2019). Validation of Burr XII inverse Rayleigh model via a modified chisquared goodness-of-fit test. Journal of Applied Statistics, 47(1), 1-32.

8. Hamedani G. G., Altun, E, Korkmaz, M. C., Yousof, H. M. and Butt, N. S. (2018). A new extended G family of continuous distributions with mathematical properties, characterizations and regression modeling. Pak. J. Stat. Oper. Res., 14(3), 737-758.

9. Hamedani G. G. Rasekhi, M., Najibi, S. M., Yousof, H. M. and Alizadeh, M., (2019). Type II general exponential class of distributions. Pak. J. Stat. Oper. Res., 15 (2), 503-523.

10. Hamedani G. G. Yousof, H. M., Rasekhi, M., Alizadeh, M., Najibi, S. M. (2017). Type I general exponential class of distributions. Pak. J. Stat. Oper. Res., 14(1), 39-55.

11. Ibrahim, M. (2019). A new extended Fréchet distribution: properties and estimation. Pak. J. Stat. Oper. Res., 15 (3), 773-796.

12. Ibrahim, M. (2020a). The compound Poisson Rayleigh Burr XII distribution: properties and applications. Journal of Applied Probability and Statistics, forthcoming.

13. Ibrahim, M. (2020b). The generalized odd log-logistic Nadarajah Haghighi distribution: statistical properties and different methods of estimation. Journal of Applied Probability and Statistics, forthcoming.

14. Ibrahim, M., Goual, H., Alotaibi, R., Ali, M.M. Rezk, H. R. and Yousof, H. M. (2020). Censored and uncensored validation for the double Burr XII model using a new Nikulin-Rao-Robson goodness-of-fit test with Bayesian and non-Bayesian estimation, Journal of Taibah University for Science, forthcoming.

15. Ibrahim, M., Yadav, A. S. Yousof, H. M., Goual, H. and Hamedani, G. G. (2019). A new extension of Lindley distribution: modified validation test, characterizations and different methods of estimation, Communications for Statistical Applications and Methods, 26(5), 473-495.

16. Korkmaz, M. C., Altun, E., Yousof, H. M. and Hamedani G. G. (2019). The odd power Lindley generator of probability distributions: properties, characterizations and regression modeling, International Journal of Statistics and Probability, 8(2), 70-89.

17. Korkmaz, M. C. Yousof, H. M. and Ali, M. M. (2017). Some theoretical and computational aspects of the odd Lindley Fréchet distribution, Journal of Statisticians: Statistics and Actuarial Sciences, 2, 129-140. 
18. Korkmaz, M. C. Yousof, H. M. and Hamedani G. G. (2018). The exponential Lindley odd log-logistic G family: properties, characterizations and applications. Journal of Statistical Theory and Applications, 17(3), $554-571$.

19. Lomax, K.S. (1954). Business failures: Another example of the analysis of failure data, Journal of the American Statistical Association 49, 847-852.

20. Murthy, D.N.P. Xie, M. and Jiang, R. (2004). Weibull Models, Wiley.

21. Yadav, A. S., Goual, H., Alotaibi, R. M. Rezk, H., Ali, M. M. and Yousof, H. M. (2020). Validation of the Topp-Leone-Lomax model via a modified Nikulin-Rao-Robson goodness-of-fit test with different methods of estimation. Symmetry, 12, 1-26. doi: 10.3390/sym12010057

22. Yousof, H. M., Afify, A. Z., Alizadeh, M., Butt, N. S., Hamedani, G. G. and Ali, M. M. (2015). The transmuted exponentiated generalized-G family of distributions, Pak. J. Stat. Oper. Res., 11 (4), $441-464$.

23. Yousof, H. M., Afify, A. Z., Alizadeh, M., Nadarajah, S., Aryal, G. R. and Hamedani, G. G. (2018a). The Marshall-Olkin generalized-G family of distributions with Applications, STATISTICA, 78(3), 273 - 295.

24. Yousof, H. M., Altun, E. and Hamedani, G. G. (2018b). A new extension of Frechet distribution with regression models, residual analysis and characterizations. Journal of Data Science, 16(4), 743-770.

25. Yousof, H. M., Afify, A. Z., Hamedani, G. G. and Aryal, G. (2017). The Burr X generator of distributions for lifetime data. Journal of Statistical Theory and Applications, 16, 288--305.

26. Yousof, H. M., Afify, A. Z., Alizadeh, M., Hamedani G. G., Jahanshahi, S. M. A. and Ghosh, I. (2018c). The generalized transmuted Poisson-G family of Distributions. Pak. J. Stat. Oper. Res., 14 (4), $759-779$.

27. Yousof, H. M., Altun, E., Ramires, T. G., Alizadeh, M. and Rasekhi, M. (2018d). A new family of distributions with properties, regression models and applications, Journal of Statistics and Management Systems, 21(1), 163-188.

28. Yousof, H. M., Altun, E., Rasekhi, M., Alizadeh, M., Hamedani, G. G. and Ali, M. M. (2019a). A new lifetime model with regression models, characterizations and applications. Communications in StatisticsSimulation and Computation, 48(1), 264-286.

29. Yousof, H. M., Butt, N. S., Alotaibi, R., Rezk, H. R., Alomani, G. A. and Ibrahim, M. (2019b). A new compound Fréchet distribution for modeling breaking stress and strengths data. Pak. J. Stat. Oper. Res., 15 (4), 1017-1035.

30. Yousof, H. M., Rasekhi, M., Altun, E. and Alizadeh, M. (2018e). The extended odd Frechet family of distributions: properties, applications and regression modeling. International Journal of Applied Mathematics and Statistics, 30(1), 1-30. 